\title{
Induction of Nuclear Lamins A/C in Macrophages in in Vitro Cultures of Rat Bone Marrow Precursor Cells and Human Blood Monocytes, and in Macrophages Elicited in Vivo by Thioglycollate Stimulation
}

\author{
Ruth-Ariane Röber, ${ }^{*}$ Robert K. H. Gieseler, $\dagger$ J. Hinrich Peters, $\dagger$ Klaus Weber, ${ }^{*}$ and Mary Osborn ${ }^{* 1}$ \\ *Max Planck Institute for Biophysical Chemistry, D-3400 Göttingen, Federal Republic of Germany; and †Department of Immunology, \\ University of Göttingen, $D$-3400 Göttingen, Federal Republic of Germany
}

\begin{abstract}
Hemopoietic cells from blood and bone marrow of mammals usually do not express lamins $\mathrm{A} / \mathrm{C}$ but only lamin $B$, and this feature distinguishes these cells from the vast majority of somatic cells of the adult animal, which reveal lamins $\mathrm{A} / \mathrm{C}$ as well as lamin $\mathrm{B}$. Here we have cultivaled rat bone marrow precursor cells and human monocytes isolated from peripheral blood in tissue culture supplemented with certain growth factors. These conditions allow bone marrow precursor cells and monocytes to differentiate almost quantitatively into accessory cells and/or mature macrophages. The different cell types in the cultures can be identified both morphologically and by other assays. Antibodies specific for mouse $\mathrm{A} / \mathrm{C}$ lamins, human $\mathrm{A} / \mathrm{C}$ lamins, or B lamins have been used to define the lamin complement as a function of time in culture and of cell type. A dramatic increase in lamin $\mathrm{A} / \mathrm{C}$-positive cells was observed in the first 3 days of culture with both accessory cells and macrophages expressing lamins $\mathrm{A} / \mathrm{C}$ as soon as such cell types could be identified. Parallel in vivo experiments showed that treatment with thioglycollate caused the percentage of lamin A/C-positive peritoneal macrophages to increase from 5 to $80 \%$ between Days 0 and 6. 1990 Academic Press, Ine.
\end{abstract}

\section{INTRODUCTION}

The nuclear lamina, which lines the inner side of the nuclear membrane, is involved in nuclear envelope integrity and in the anchorage of the nuclear pore complexes, and possibly also participates in the organization of interphase chromatin (for review, see Ref. [1]). The subunits of the lamina, the so-called lamins, have been extensively analyzed in somatic cells of mammals and chicken. While both reveal a single lamin A, only mammals display the $\mathrm{C}$ lamin. Lamin $\mathrm{C}$ is a truncated form which differs from lamin A only at the carboxyterminal end. It seems to arise by a differential RNA

\footnotetext{
${ }^{1}$ To whom reprint requests should be addressed.
}

processing step $[2,3]$. The concept of two lamin $B$ forms $\left(B_{1}\right.$ and $\left.B_{2}\right)$ encoded by different genes was first established for chicken $[4,5]$. Recent two-dimensional gel studies extended this view to mammalian lamin B [6] and protein sequence data have defined the two murine $\mathrm{B}$ forms [7]. One, corresponding to a known murine lamin B cDNA clone [8], is highly related to chicken lamin $B_{1}$, while the other closely resembles chicken lamin $B_{2}$.

Functionally, the most striking difference between lamins $A / C$ and $B$ lamins is their differential behavior during mitosis [9]. While $\mathrm{B}$ lamins stay membrane bound, lamin $\mathrm{A} / \mathrm{C}$ becomes soluble. Recent evidence seems to connect this difference with the fate of the CXXM motif at the carboxyl-end of lamins A and B. This motif sequence is subject to multiple post-translational modification steps (farnesylation, proteolytic removal of the last three residues and $O$-methylation of the cysteine) $[10,11]$. The modified cysteine is retained in lamins $B$, while a further proteolytic maturation removes the membrane binding-site from the lamin $A$ precursor upon maturation [11-13]. Since lamin C as a "truncated" form lacks this sitc altogether one could envision that the interaction of the lamina with the nuclear membrane involves the sticky end of lamins B as well as a $58-\mathrm{kDa}$ lamin receptor, which again is lamin $\mathrm{B}$-specific [14]. This scenario can also accommodate results on lamin expression during mammalian and avian embryogenesis as well as data on adult tissues and established cell lines. Lamin B is constitutively expressed in all cells while lamins $A / C$ are acquired only upon tissue maturation. For example, lamin $\mathrm{A}$ is absent in early chick embryo [15] and lamins A/C are not found between the blastocyst stage and Day 8 of the mouse embryo [16, 17] (for similar results on cow and pig embryo see Ref. [18]). In subsequent stages of murine embryogenesis the time of onset for lamin $\mathrm{A} / \mathrm{C}$ expression is tissue dependent [17] but even in the adult animal most cell types of the hemopoietic system-except the terminally differentiated erythroblasts-reveal only lamins $B$ and not lamin $A / C$ [6]. These results are com- 
patible with the speculation that lamins $\mathrm{A} / \mathrm{C}$, which seem to be acquired only in differentiated cells, provide an addition to a general lamina based on lamins B.

Most cell lines derived from mammalian somatic cells express lamins $\mathrm{A} / \mathrm{C}$ while a few hemopoietic cell lines lack lamins $A / C[6,19,20]$. These results, generally obtained by immunofluorescence microscopy, are supported by several immunoblotting analyses and in isolated instances also by Northern blots. Thus far acquisition of lamins $\mathrm{A} / \mathrm{C}$ in vitro has been documented only in two cases, and in both instances for established cell lines. Thus teratocarcinoma cells upon induction of differentiation by retinoic acid express lamin A/C $[17,21$, 22]. HL60 cells treated with phorbol ester also acquire lamins A/C [20].

Here we have examined the acquisition of lamins $A / C$ in vitro using hemopoietic cells isolated directly from rat and man. We have followed the differentiation of rat bone marrow cells into mature macrophages in culture [23] and also the development of cultured human monocytes into accessory cells and macrophages [24]. Accessory cells are defined as a cell lineage derived from monocytes, which have a high capacity to induce antigenic or mitogenic lymphocyte stimulation. We show that in both systems the percentage of lamin A/C-positive cells increases parallel to the emergence of the differentiated cell types. Additionally we elicited in vivo mouse peritoneal macrophages with thioglycollate and could observe aquisition of lamin $\mathrm{A} / \mathrm{C}$ in cells of the treated animals.

\section{MATERIALS AND METHODS}

Animals. LEW.1W and LEW.1A rats were sacrificed by $\mathrm{CO}_{2}$ excess. Animals younger than 13 weeks were used for maximum yields of bone marrow cells. Usually $4.5-9.5 \times 10^{7}$ bone marrow cells were obtained from the femurs and tibias of each rat.

Cultures of rat bone marrow cells (BMC). The preparation and cultivation of cells have been described in detail elsewhere [23]. Briefly, BMC were flushed from femurs and tibias with cold 80/20 medium without serum (80\% RPMI 1640 and $20 \%$ medium 199 (Earle's salts)) into a culture dish. Single-cell suspensions were obtained by passing the bone marrow through a syringe fitted with a number $25 \mathrm{G} \frac{7}{8}$ needle until aggregates were dissociated, as confirmed by microscopic examination. $\mathrm{BMC}$ were washed three times by centrifugation in $80 / 20 \mathrm{me}-$ dium at $300 \mathrm{~g}$ for $10 \mathrm{~min}$ at $4^{\circ} \mathrm{C}$. Erythrocytes and some progenitor cells were lysed with $0.18 \mathrm{M} \mathrm{NH}_{4} \mathrm{Cl}$ buffer. After centrifugation the remaining cells were placed in a $10-\mathrm{cm}$-diameter petri dish in $20 \mathrm{ml}$ $80 / 20$ medium plus $10 \%$ bovine serum and allowed to adhere for $1 \mathrm{~h}$ at $37^{\circ} \mathrm{C}$. The nonadherent cells (BMC $\mathrm{Ad}^{-}$) were adjusted to a concentration of $1 \times 10^{6} / \mathrm{ml}$ in $80 / 20$ medium and $200 \mu \mathrm{l}$ was placed either in wells of a 96-well microtiter plate or in a compartment of a silicon rubber form (Flexiperm, Hereaus, FRG) in a 10-ml petri dish. Mature macrophages were obtained by allowing BMC Ad cells to differentiate for $5-20$ days in $80 / 20$ medium supplemented with $10 \%$ bovine serum and the growth factors s-mu-M-CSF and s-mu-multi-CSF [25]. In some instances cultures were also supplemented with vitamins $\mathrm{E}$ and $\mathrm{D}_{3}$ and linoleic acid.

Humun monocyte cultures. Monocytes were prepared from the peripheral blood of healthy blood donors. Mononuclear cells were obtained after centrifugation of venous blood on Ficoll-Hypaque (Lym- phoprep. Nyegaard, Oslo). Cells were placed at a density of $1 \times 10^{6} / \mathrm{ml}$ on tissue culture dishes containing glass coverslips and allowed to attach for $60 \mathrm{~min}$ at $37^{\circ} \mathrm{C}$. Nonadherent cells were removed by gentle washing. The adherent population was $10 \%$ of the initial cell number and consisted of $95 \%$ monocytes. Cells were incubated for times up to 20 days in $80 / 20$ medium supplemented with $20 \%$ human $\mathrm{AB}$ serum or in medium MCDB 302 (Sigma, Deisenhofen, FRG), which is a defined medium lacking serum.

Characterization of cell types. The different cell types present in the BMC and human monocyte cultures were characterized by the following criteria (for details, see Refs. [23, 24]). (a) Morphology in phase-contrast microscopy; (b) May Grünwald-Giemsa stain; (c) $\alpha$ naphthyl butyrate esterase ( $\alpha \mathrm{NBE}$ ) activity. The Koski method [26] was modified by using the Technicon test kit. Cells revealing esterase activity show brown cytoplasmic staining. (d) Cl. II antigens (class II antigens of the rat RT 1 gene complex-chromosome 14) were detected by a Cl. II-specific monoclonal mouse anti-rat IgG (MRC OX-6 Serotech, Camon, Wiesbaden, FRG) in a biotin-streptavidin-peroxidase immunostaining procedure [27]. (e) Phagocytosis of latex beads (Sigma). Latex beads ( 0.8 or $0.4 \mu \mathrm{m}$; Sigma) were opsonized with a polyclonal rat IgG and washed with PBS. Opsonized beads were added to the cultures. Cultures were examined $1 \mathrm{~h}$ later for $\mathrm{Fc}$ receptor-dependent phagocytosis. (f) An accessory cell-lymphocy le cooperation assay was used to assess accessory activity. Accessory cells were stimulated with sodium periodate, which was subsequently removed by washing. This caused lymphocytes added to the cultures to proliferate and the proliferation was quantitated by measuring $\left[{ }^{3} \mathrm{H}\right]$ thymidine incorporation over a $24-\mathrm{h}$ period.

Thioglycollate-elicited peritoneal macrophages. These were obtained by lavage 3 and 6 days after an intraperitoneal injection of 1.5 $\mathrm{ml}$ of $3 \%$ Brewer's thioglycollate medium (Difco, Detroit, MI, U.S.A.) by the method of Gallily and Feldman [28]. This part of the study was done in specific pathogen-free NMRI mice. Cells from stimulated mice and control animals were washed twice with PBS and seeded either in DME without serum and $25 \mathrm{~m} M$ Hepes buffer or in cRPMI medium with $5 \%$ FCS in a $5-\mathrm{ml}$ petri dish at a density of $2 \times 10^{5}$ cells $/ \mathrm{ml}$ on glass coverslips. Macrophages were allowed to adhere to the coverslips for about $2 \mathrm{~h}$. Then the coverslips were flushed free of as many as possible of the loosely attached lymphocytes also present in the cultures by washing in PBS, and the macrophages processed for immunofluorescence procedures as described below.

Antibodies. Lamin antibodies were derived from two fusions with spleen cells from BALB/c mice, immunized with the nuclear lamin fraction prepared from liver by the procedure of Dwyer and Blobel [29]. mAB346 raised against rat lamins gave a typical peripheral nuclear staining on rat RMCD cells in immunofluorescence microscopy and was shown in two-dimensional immunoblots of mouse and rat lamins to recognize lamins $A$ and $C$ but not lamin $B$ [17]. mAB636 raised against pig lamins revealed nuclear lamin staining of pig LLCPK 2 cells and of human HeLa cells. In two-dimensional blots it recognized lamins A/C of pig liver and human HeLa cells (see Results). The polyclonal lamin B-specific rabbit antibody was a generous gift from Drs. Robert Shoeman and Peter Traub [30]. The guinea pig antibody to vimentin is that described in Ref. [31].

FITC-labeled goat anti-mouse IgG, goat anti-rabbit IgG, and rabbit anti-guinea pig IgGs (Cappell Laboratories, Cochraneville PA, U.S.A.) were used at dilutions hetween 1:20 and 1:60.

Gel electrophoresis and immunoblotting. Two-dimensional nonequilibrium gradient gel electrophoresis (Nephge) used ampholines in the $\mathrm{pH}$ range 3.5-10 (Pharmacia/LKB, Freiburg, FRG) and $8 M$ urea in the first dimension, and sodium dodecyl sulfate (SDS)-polyacrylamide gel electrophoresis ( $10 \%$ acrylamide and $0.8 \%$ bisacrylamide) in the second dimension. Polypeptides were electrophoretically transferred to nitrocellulose sheets using a transfer buffer containing $25 \mathrm{mM}$ Tris base, $192 \mathrm{mM}$ glycine, $0.01 \%$ SDS, and $20 \%$ methanol. Transferred proteins were visualized by staining the sheets with Ponceau S. The positions of the relevant polypeptides were marked 
with a needle. Immunoblotting was by standard procedures using peroxidase-labeled second antibodies (see Ref. [6]).

Immunofluorescence microscopy. BMC cells in tissue culture petri dishes divided into compartments by silicon rubber grids were spun at $25 \mathrm{~g}$ for $1 \mathrm{~min}(\sim 400 \mathrm{rpm}$ in a Heraeus Laboratory centrifuge) to ensure that the cells adhered to the plastic surface. After removing the medium, cells were air dried and then fixed with methanol at $-10^{\circ} \mathrm{C}$ for $10 \mathrm{~min}$. Cells were subsequently washed with phosphatebuffered saline without calcium and magnesium (PBS) at $4^{\circ} \mathrm{C}$ and incubated with mAB346 overnight at $4^{\circ} \mathrm{C}$ in a wet chamber. In experiments using the other antibodies, cells were methanol fixed, air dried, and then incubated with the appropriate first antibody at $37^{\circ} \mathrm{C}$ for 1 h. After incubation with the primary antibody, cells were washed three times with PBS and then incubated for $30 \mathrm{~min}$ at $37^{\circ} \mathrm{C}$ with the appropriate fluorescein-coupled second antibody. After a further wash with PBS, the nuclei were counterstained for $10 \mathrm{~min}$ at room temperature with the Hoechst dye 33258. Cells were mounted without further washing with Mowiol 4.88 (Hoechst AG, Frankfurt, FRG). Mouse peritoneal macrophages on glass coverslips were fixed and stained with $\mathrm{mAB} 346$ using the procedures given above. Blood monocytes on glass coverslips were fixed with methanol at $-10^{\circ} \mathrm{C}$ for $5 \mathrm{~min}$ and with acetone at $-10^{\circ} \mathrm{C}$ for $10 \mathrm{~min}$. Cells were air dried and incubated with $\mathrm{mAB} 636$ at $37^{\circ} \mathrm{C}$ for $1 \mathrm{~h}$. Incubation with second antibody and further staining followed the procedure given above.

\section{RESULTS}

\section{Isolation of $m A B 636$ Specific for Human Lamins $A / C$}

$\mathrm{mAB} 636$ was selected from a fusion in which a partially purified pig liver lamin preparation was used as antigen. It showed a typical nuclear lamin staining of pig LLCPK 2 cells and of human HeLa cells in immunofluorescence microscopy. In a two-dimensional blot of a pig liver lamin fraction it recognized lamins $\mathrm{A} / \mathrm{C}$, but did not recognize the lamin B spots (Fig. 1).

\section{Rat Bone Marrow Cell Culture}

Bone marrow precursor cells of the monocyte/macrophage lineage in Lewis rats quantitatively differentiated in vitro into veiled accessory cells and then into macrophages when medium $80 / 20$ supplemented with $10 \%$ bovine serum was used. A high yield of mature macrophages was obtained when BMC $\mathrm{Ad}^{-}$cells were cultured in 96-well dishes in medium $80 / 20$ containing $10 \%$ bovine serum, s-mu-M-CSF, and s-mu-multi-CSF [23]. Initially, the cells were seeded at a density of $2 \times 10^{5} / 200-\mu 1$ well. Within the first 5 days the cell number decreased and at Day 10 the diferentiated cell populations plateaued at approximately $1 \times 10^{4}$ cells $/ 200 \mu \mathrm{l}$ well (Fig. 2). Cells in this system survived for up to 70 days. By growing the cells in silicon grids fixed to plastic petri dishes, immunofluorescence procedures could be performed without removing the cells from the plastic surface and thus without disturbing their morphology. Cells grown under such conditions also showed the initial decrease in cell number, but at 10-12 days the cell density plateaued at a value equal to that reached in the 96-well microculture dishes (Fig. 2).
Cell type kinetics. May Grünwald-Giemsa staining was used as the first assay to distinguish the different cell types in the culture (Table 1). At Day 0, the starting cell population contained $75 \%$ early bone marrow precursors, which were not further classified. Anulocytes (e.g., granulocytes with a ring-shaped nucleus in rodents, which correlate to polymorphs in man) accounted for $20 \%$, while the other $5 \%$ were induced promonocytes, monocytes, and a few macrophages (cf. phase micrograph in Fig. 3e). After 2-3 days in the presence of serum, the majority of cells showed the characteristic features of accessory cells. Such cells were characterized by their irregular and often stretched shapes and by the protrusions resembling delicate "veils." At this time large round cells with typical granules and a flattened appearance were also present. These early differentiated macrophages were scattered between the veiled accessory cells. Within the next $2-3$ days most of the veiled cells turned into mature macrophages (Fig. $3 \mathrm{i}$ and Table 1). After 12 days in culture almost all cells still present had differentiated into macrophages (Fig. 31 ). Since the total cell number did not increase but remained approximately the same from Day 10 until the end of the observation time at Day 25 (Fig. 2), we most likely observed a conversion from accessory cells to macrophages rather than the outgrowth of the macrophages as a new population of cells. The inclusion of colony-stimulating factors in the medium results in the survival of only the myeloid cells.

Additional assays were used to positively identify accessory cells and macrophages and to distinguish these two cell types from one another and from their bone marrow precursors (see Methods). Accessory cells were strongly positive for class II antigen, while other cell types were negative or stained only very weakly. Macrophages express only low amounts of class II antigens. Accessory cells were also characterized by their accessory function in a cell cooperation assay which measured the accessory cell lymphocyte stimulation by $\left[{ }^{3} \mathrm{H}\right]$ thymidine incorporation. The early peak of high accessory activity detected within the cultures grown in the presence of serum was paralleled by the transient appearance of accessory veiled cells. Thereafter, as macrophages began to form the predominant myeloid cell population, accessory activity decreased almost to zero. Macrophages were positively identified by their ability to phagocytose opsonized latex particles, since accessory cells and precursor cells did not do so. Furthermore, of the four cell types only macrophages and monocytes were strongly positive when tested for $\alpha$-NBE, while accessory cells were much less strongly stained. Fifty percent of the cells stained positively during the entire culture period, and on Days 2 and 3 of culture up to $70 \%$ of cells stained positively for $\alpha-\mathrm{NBE}$.

Acquisition of $A / C$ lamins in bone marrow cell cultures. Using the culture system described above, in 


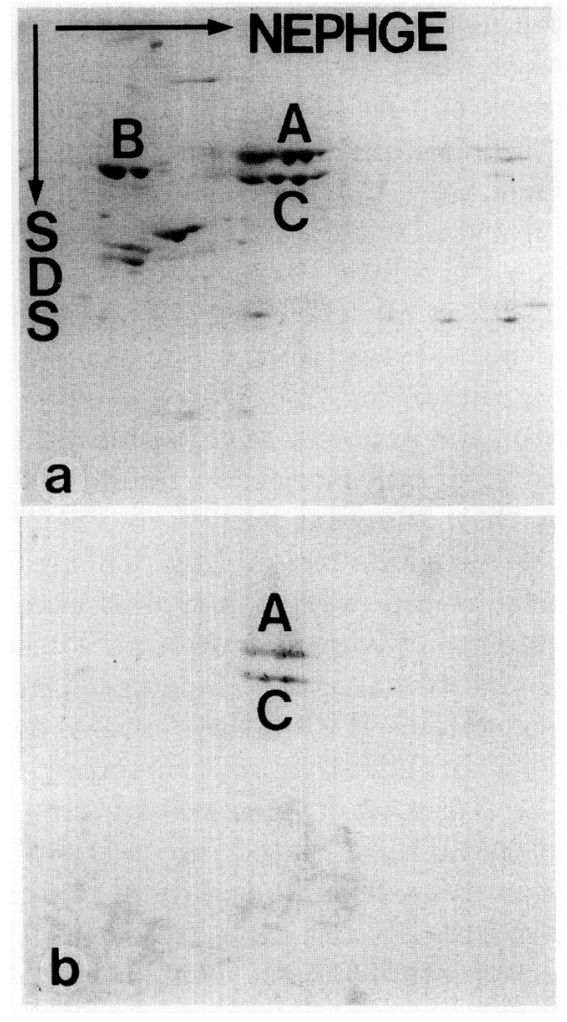

FIG. 1. 'I'wo-dimensional blots of pig lamins with mAB636. (a) A crude preparation of lamins from pig liver stained with Coomassie blue. (b) The same lamin fraction immunoblotted with mAB636. A, B, and $\mathrm{C}$ indicate positions of lamins $\mathrm{A}, \mathrm{B}$, and $\mathrm{C}$, respectively.

which rat bone marrow precursor cells differentiate into mature macrophages in vitro, the question was posed whether lamin expression was affected by the differentiation process. Figures $3 a-3 d$ show a population of freshly prepared BMC stained in indirect immunofluorescence microscopy with the $\mathrm{mAB} 346$. The striking features of these cells included their small size, visible in living cultures (Fig. 3e) or in the phase micrographs (Fig. 3c), the characteristic shape of their nuclei (Figs. $3 \mathrm{~b}$ and $3 \mathrm{~d}$ ) and their loose attachment to the substra-

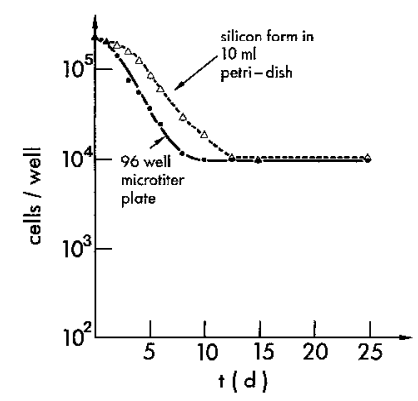

FIG. 2. Kinetics of rat bone marrow cultures. Cells per well plotted as a function of days in culture in either 96 -well microtiter plates or $10-\mathrm{ml}$ plastic petri dishes divided into compartments by silicon rubber grids.
TABLE 1

Cell Types in Rat Bone Marrow Cell Cultures as a Function of Days in in Vitro Culture Expressed as Percentages of Total Cell Number

\begin{tabular}{|c|c|c|c|c|}
\hline Cell types ${ }^{a}$ & $\begin{array}{l}\text { Lamin A/C } \\
\text { status }^{b}\end{array}$ & Day 0 & Day 6 & Day 12 \\
\hline $\begin{array}{l}\text { Early bone marrow } \\
\text { precursor cells }\end{array}$ & - & 75 & 18 & 5 \\
\hline Granulocytes & - & 20 & 12 & 25 \\
\hline Promonocytes & +1 & & & \\
\hline Monocytes & + & 5 & 70 & 70 \\
\hline Accessory cells & $+\}$ & & & \\
\hline Macrophages & $+\int$ & & & \\
\hline
\end{tabular}

tum. At Day 0, almost all cells were negative when tested with the lamin A/C-specific mAB346 (compare Fig. 3a with Figs. $3 \mathrm{~b}$ and $3 \mathrm{c}$ ). In contrast, strong nuclear staining of all interphase cells was seen with the polyclonal lamin B specific antibody (Fig. 3d). On Day 1, some $6 \%$ of cells showed a bright typical nuclear lamin ring, when incubated with mAB346. These lamin A/C-positive cells could be identified in phase contrast as mature macrophages which were obviously already primed for differentiation in vivo. On Day 3,63\% of the cells were A/C lamin-positive when tested with mAB346. On Day 6 virtually all cells of the preparation were stained by mAB346 (97\%) (compare Fig. 3f with the Hoechst nuclear staining of the same cells in Fig. 3g). Comparison with the phase micrograph of the same cells in Fig. 3h shows that the lamin A/C-positive cells belonged to the monocyte/macrophage cell population as shown by their flattened appearance and differentiated morphology. The percentage of lamin A/C-positive cells remained greater than $90 \%$ until the end of the observation period at Day 12. The staining patterns on Days 12 given in Figs. 3j-3k again show that cultured cells of the monocyte/macrophage type are lamin A/C-positive. All cell types were positive with the lamin B polyclonal antibody at all times tested (0-12 days) (cf. Fig. 3d).

Table 1 shows that by May Grünwald-Giemsa staining at Days 6 and 12 about $70 \%$ of the cells fell into the lamin A/C-positive category, i.e., monocytes, accessory cells, and macrophages. In contrast, in the samples analyzed by immunofluorescence, $90.96 \%$ of the cells were lamin A/C-positive. The discrepancy between these numbers is explained by the selective loss of the more loosely attached early bone marrow precursor cells and the granulocytes during the immunofluorescence procedure. A comparison of Fig. 3i (phase contrast of the living culture) with Fig. 3h (phase micrograph of the culture) shows a selective loss of the more rounded cells. From the additional assays used to distinguish the dif- 

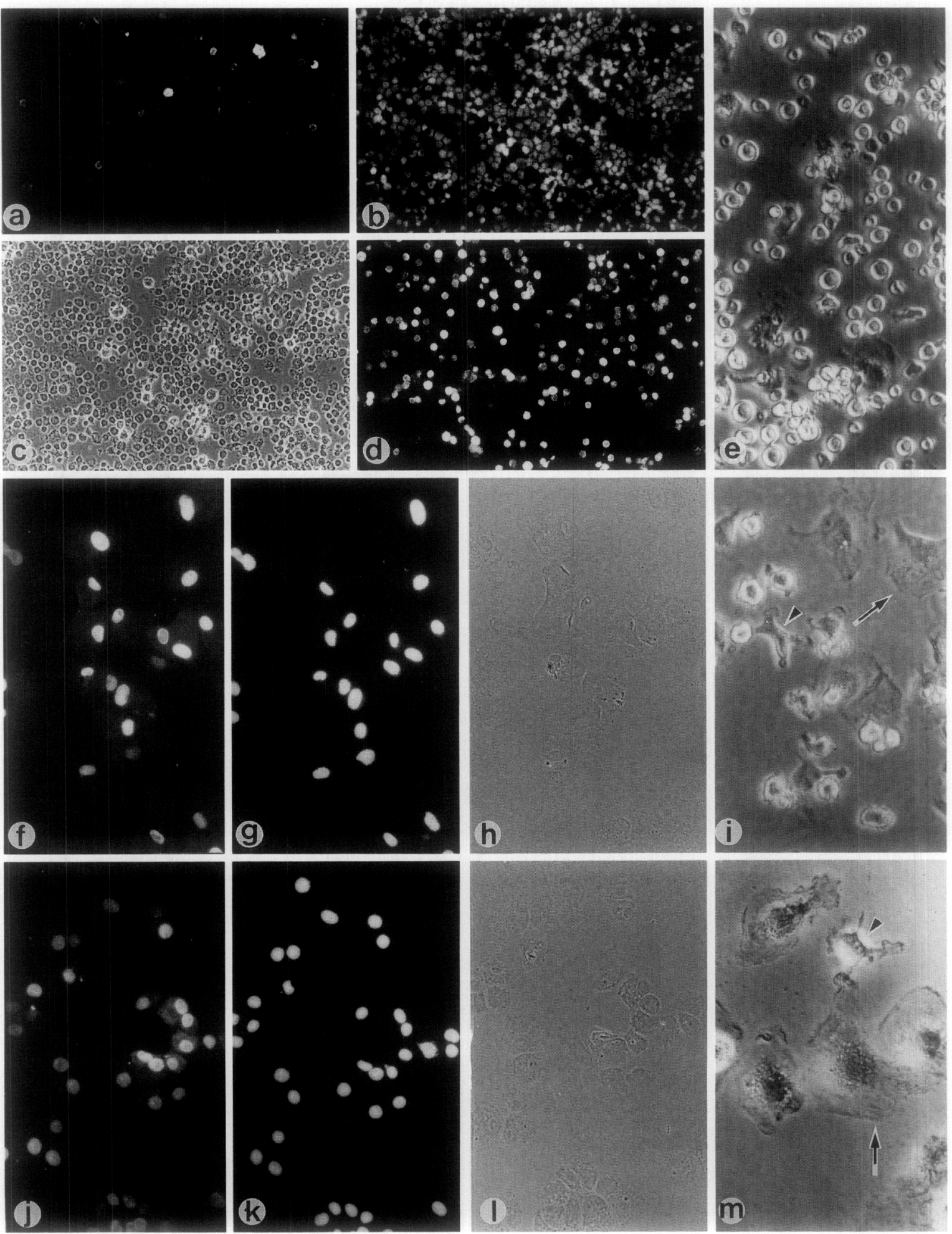

FIG. 3. Immunofluorescence and phase microscopy of rat bone marrow precursor cells and their derivatives after different times of cuiture on plastic. (a-e) Day 0. (a) mAB346, recognizing lamins A/C, stains only a few cells (compare a with the Hoechst stain in b or with the phase image in $c$ of the same cells). (d) In contrast the rabbit antibody specific for lamin $B$ decorates almost all nuclei when tested in parallel. (e) Phase-contrast of live cells photographed in culture; note the round shape and translucent rims, indicating that they are loosely attached. (i-i) Day 6. (f) Almost all cells show strong staining of lamins A/C with mAB346. Compare with the Hoechst stain in $g$ and the phase micrograph in $\mathrm{h}$ of the same cells. (i) The live cells photographed in culture are not so uniform. Macrophages are recognizable by their flattened appearance (arrows) while accessory cells are distinguished by veiled cell protrusions (arrowheads). Some rounded cells are also present. (j-m) Day 12. (j) Almost all cells are positive for lamins $A / C$ when tested with the $\mathrm{mAB} 346$ (compare to Hoechst stain in $\mathrm{k}$ and the phase micrograph in 1 of the same cells). The cells adhere tightly to the plastic surface. $(\mathrm{m})$ In cell culture the population has also changed in comparison to that at Day 6. The macrophages have enlarged and are firmly attached to the surface, although occasional accessory cells are still present. Magnifications: $(\mathrm{a}-\mathrm{d}, \mathrm{f}-\mathrm{h}, \mathrm{j}-\mathrm{l}) \times 180 ;(\mathrm{e}, \mathrm{i}, \mathrm{m}) \times 720$. 

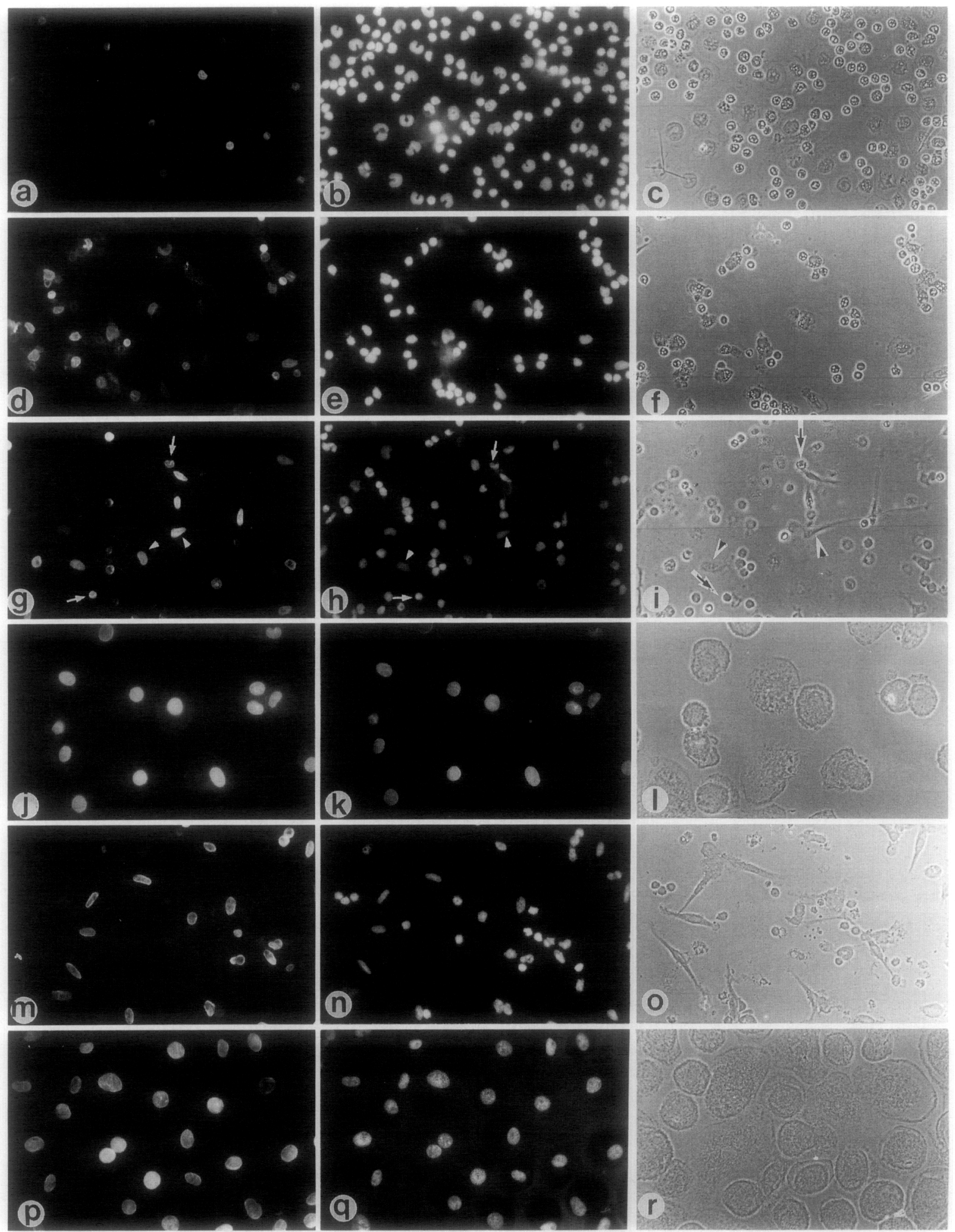

FIG. 4. Immunofluorescence and phase microscopy of human monocytes and their derivatives after different times of culture on glass coverslips in two different media. (a-c) Day 0. (a) mAB636 specific for lamins A/C stains only a small percentage of cells. A comparison to the Hoechst stain of the same cells in b shows that the very few lamin A/C-positive cells in a are not monocytes (identified by their horseshoeshaped nuclei) but rather represent a minor fraction of the lymphocyte population. (c) Phase micrograph of cells in a and b. (d-i) Day 2. (d-f) Cells with human AB serum. (d) mAB636 decorates occasional lymphocytes as well as larger cells with larger, sometimes horseshoe-shaped nuclei (cf. parallel Hoechst stain in e). (f) The phase micrograph of the same cells shows that larger nuclei positive for lamins A/C belong to cells which have begun to spread on the surface. ( $\mathrm{g}-\mathrm{i}$ ) Cells in serum-free medium. (g) Heterogeneous population of cells which are positive for lamins A/C with mAB636. In the Hoechst (k) and phase images (i) the lamin A/C positive cells can be identified as lymphocytes (arrows), monocytes, and accessory cells (arrowheads). ( $j-0)$ Day 7. (j-l) Cells in human AB serum. (j) mAB636 shows almost all cells are positive for lamins A/C. In the Hoechst stain (h) and in the phase micrograph (1) the A/C positive cells can be identified as mature macrophages, which are now the major cell type present. (m-o) Cells grown in serum-free medium. $(\mathrm{m}) \mathrm{mAB} 636$ stains occasional lymphocytes and almost all cells with larger elongated nuclei. The nuclear stain in $n$ and the phase images in o show that these are accessory cells. (p-r) Day 13, cells grown in human AB serum. (p) mAB636 stains all cells positively. The nuclear stain (q) and the phase images (r) show that the lamin A/C-positive cells are macrophages. Magnification $\times 180$. 


\section{TABLE 2}

Acquisition of Lamins $\mathrm{A} / \mathrm{C}$ during in Vitro Cultivation and Differentiation of Rat Bone Marrow Precursor Cells and $\mathrm{Hu}$ man Blood Monocytes

\begin{tabular}{|c|c|c|c|}
\hline \multirow[b]{2}{*}{ Days in culture } & \multirow{2}{*}{$\begin{array}{l}\text { Rat bone marrow } \\
\% \mathrm{~A} / \mathrm{C} \text { positive cells }\end{array}$} & \multicolumn{2}{|c|}{$\begin{array}{l}\text { Human monocytes } \\
\% \mathrm{~A} / \mathrm{C} \text { positive cells }\end{array}$} \\
\hline & & $\mathrm{AB} \mathrm{Ser}{ }^{+}$ & $\operatorname{Ser}^{-}$ \\
\hline 0 & 0 & 0 & 0 \\
\hline 1 & 6 & & \\
\hline 2 & & 11 & 31 \\
\hline 3 & 63 & & \\
\hline 5 & 62 & & \\
\hline 6 & 97 & & \\
\hline 7 & & $>80$ & $>90$ \\
\hline 8 & 90 & & \\
\hline 10 & 96 & & \\
\hline 12 & 90 & $>90$ & \\
\hline
\end{tabular}

Note. The percentages of lamin A/C positive cells were counted in relation to cells revealing monocyte/accessory cell/macrophage features by Hoechst staining and phase image. Lymphocytes are therefore excluded.

ferent cell types, it is clear that these rounded cells correspond to the precursor cells and to granulocytes.

\section{Human Monocyte Cultures}

Cell type kinetics. Monocytes isolated from peripheral blood differentiated into accessory cells when the cells were cultured in serum-free medium or into mature macrophages when the culture medium was supplemented with human $A B$ serum. In serum-free culture, conversion of monocytes to cells of increased accessory function with the appearance of veils as the predominant morphologic feature took place during the first 2 days of culture. Dendritic elongations and a stretched fibroblast-like shape were usually apparent after 1 week of culture. Monocytes forced into macrophage development by human $A B$ serum displayed enhanced accessory activity during the first 1-2 days of culture, as did the cells grown under serum-free conditions [24]. This accessory state could also be followed by morphological criteria, as it is characterized by rounding up of the cells, low adherence, and the expression of veils after $12-96 \mathrm{~h}$ in cuiture. At the same time, cells began to display macrophage-like features. These included a round, flattened shape, ruffled membranes, phase dense granules, and stronger attachment to the substratum.

Cell type identification. Three assays were used to positively identify accessory cells and macrophages. Accessory cells were very strongly stained with antibodies to class II antigen, whereas the other cell types, i.e., macrophages and part of the bone marrow precursor cells, were positive but less strongly stained. Monocytes and mature macrophages showed only low lymphocyte stimulatory activity, but cells kept under serum-free condi- tions revealed enhanced accessory activity starting on Day 1 of culture. Macrophages also showed Fc receptordependent phagocytosis as assayed by their ability to phagocytose opsonized latex particles.

The human monocyte preparation, isolated from peripheral blood, also contained a considerable number of lymphocytes (Fig. 4c). However, the munocytes can be easily identified by the horseshoe shape of their nuclei (Fig. 4b).

Acquisition of $A / C$ lamins during in vitro cultivation of human monocytes. The cells were first assayed $5 \mathrm{~h}$ after being placed in culture. At this time a small percentage of cells already revealed nuclear lamin staining when tested with $\mathrm{mAB} 636$, specific for human lamin A/C. A careful comparison of $\mathrm{mAB} 636$-staining with its Hoechst counterpart (Fig. 4b), showed that the few lamin A/C-positive cells were not monocytes but rather a subpopulation of lymphocytes. On culture Day 2 , cells grown in medium supplemented with human $\mathrm{AB}$ serum had already begun to differentiate into macrophages, and macrophages could be distinguished morphologically (Fig. 4f). Accessory cells were also present and could be identified hy their elongated shape and their protrusions (Fig. 4f). This cell type was abundant in serum-free media, in which the macrophages were not seen (Fig. 4i). By the time macrophages as well as accessory cells could be identified by morphological criteria, the two cell types were lamin A/C-positive. Most lymphocytes still present in the cultures were lamin $\mathrm{A} / \mathrm{C}$ negative. On Day 8, the differences in morphology of cells cultured in the two media became more obvious (compare the phase micrographs in Fig. 41 and Fig. 40). With human $A B$ serum, cells differentiated into mature macrophages (Fig. 41), whereas without serum, only cells at the accessory stage were found (Fig. 40). Again both the mature macrophages and the accessory cells are lamin A/C-positive (compare Figs. $4 \mathrm{j}$ and $4 \mathrm{~m}$ ). On Day 12 all macrophages present in the human $A B$ serum cultures were positive for lamins $\mathrm{A} / \mathrm{C}$ (Figs. $4 \mathrm{p}$ and $4 \mathrm{r}$ ).

Cells that could be identified morphologically as accessory cells or macrophages were invariably lamin A/ C-positive (Fig. 4). Results of determining the percentage of lamin A/C-positive cells after different times in culture are shown in Table 2 . The percentage of lamin A/C-positive cells was counted in relation to the total monocyte/macrophage/accessory cell population. Thus lymphocytes which were present in the culture and which occasionally reveal lamin A/C-positive nuclei were not included. On Day 0, monocytes were not decorated by the lamin $\mathrm{A} / \mathrm{C}$ antibodies. In contrast on Day 2, $11 \%$ of the monocytes grown in the human $\mathrm{AB}$ serum depleted condition stain for lamin $A / C$. Comparing these percentages with Figs. $4 \mathrm{~d}-4 \mathrm{f}$ and $4 \mathrm{~g}-4 \mathrm{i}$, it becomes clear that the lamin $\mathrm{A} / \mathrm{C}$-positive cells belong to the macrophage and accessory cell types. At Day 6 and thereafter, more than $80 \%$ of the cell population was 

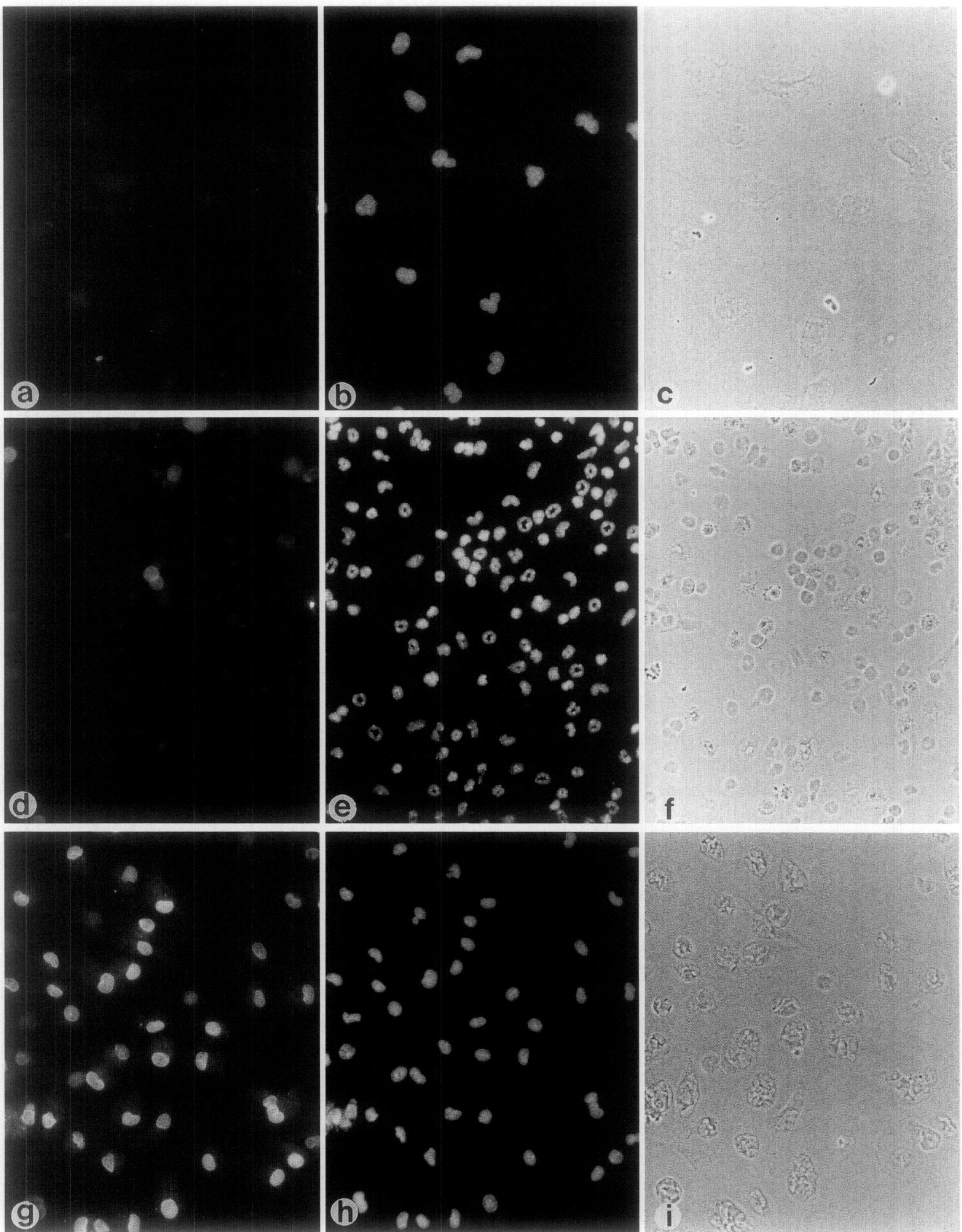

FIG. 5. Immunofluorescence of mouse peritoneal macrophages, unstimulated (a-c), and 3 (d-f) and 6 days ( $\mathrm{g}-\mathrm{i}$ ) after thioglycollate injection. (a) mAB 346 specific for lamins A/C does not recognize nuclei of unstimulated peritoneal macrophages. (b) Parallel Hoechst stain. Note kidney-shaped nuclei in some cells. (c) Phase image of cells in a and b. (d) Macrophages 3 days after stimulation by thioglycollate do not display strong lamin decoration when tested with $\mathrm{mAB} 346$, recognizing lamins $\mathrm{A} / \mathrm{C}$. (e) Parallel Hoechst stain displays small nuclei, which belong to small round cells as revealed by phase image in $\mathrm{f}$. (g) Macrophages 6 days after stimulation by thioglycollate show strong lamin $A / C$ decoration when stained by mAB346. Comparing $\mathrm{g}$ with the Hoechst counterstain in h shows that nearly $80 \%$ of the cells are positive for lamins A/C. (i) In phase, the macrophages appear as large flattened cells. Magnification $\times 225$. 
positive for lamin A/C. Their morphology (see Figs. 4j$4 r)$ identifies these cells as macrophages and accessory cells in both types of culture conditions.

Lamin A/C expression in macrophages from thioglycollate-treated mice. Peritoneal macrophages flushed out of unstimulated mice could easily be distinguished from those elicited in thioglycollate-treated animals. Macrophages from unstimulated mice showed large, often kidncy-shaped nuclci (compare Hoechst staining in Fig. 5b). In immunofluorescence, $\mathrm{mAB} 346$, decorating lamins $\mathrm{A} / \mathrm{C}$, left almost all cells negative (Fig. 5a). Some cells showed a blurred faint background staining in the nuclear area, and occasionally one or the other cell had a weak but clear lamin-like ring. Three days after thioglycollate injection macrophages formed a larger percentage of the seeded cells (Fig. 5d). Their nuclei seemed smaller than those of unstimulated specimens (compare Figs. 5b and 5e). Lamin A/C expression was seen only in occasional nuclei. The picture changed dramatically 2 days later. Eighty percent of the macrophages flushed out of the peritoneum 5 days after thioglycollate injection showed a strikingly strong decoration by the lamin $\mathrm{A} / \mathrm{C} \mathrm{mAB} 346$ (Fig. 5g).

\section{DISCUSSION}

IIere we have demonstrated that certain hemopoietic cell types, which lack lamins $\mathrm{A} / \mathrm{C}$ in vivo begin to express these nuclear protcins when cultivated under defined conditions in vitro. Both rat bone marrow-derived cells, as well as human blood monocytes, differentiate in vitro, resulting in the appearance of accessory cells and macrophages in the culture. As soon as such cells can be identified in the cultures either morphologically or by other assays, they appear to express lamins A/C. In addition, a certain small fraction of the lymphocyte population is lamin A/C-positive already in vivo. By far the majority of macrophages and monocytes are negative for lamin $\mathrm{A} / \mathrm{C}$ when isolated directly from pathogenfree mice. Interestingly, in mice treated by thioglycollate, lamin $\mathrm{A} / \mathrm{C}$ expression increases as a function of time of treatment and reaches $80 \%$ after 6 days. In contrast all cells express lamin $B$ constitutively at all times tested.

During murine embryogenesis the time of lamin $\mathrm{A} / \mathrm{C}$ acquisition is tissue dependent and often seems to coincide with major changes in tissue structure; e.g., it is seen around Day 13 in the skeletal muscle myogenesis when also muscle-specific proteins such as titin are acquired. Lamin A/C appearance at Day 16 in the epidermis coincides with the formation of a double layer of epidermal cclls (periderm). In the brain most cells develop lamin $\mathrm{A} / \mathrm{C}$ well after birth. Thus acquisition of lamin $\mathrm{A} / \mathrm{C}$ often occurs at a time relatively long after the commitment of cells to a particular differentiation pathway (as judged for instance by expression of partic- ular IF proteins) and when it may be advantageous to restrict the plasticity of cells for further developmental events. Those cells of the hemopoietic and immune systems, which are negative for lamin $\mathrm{A} / \mathrm{C}$ in vivo, may well have the potential to respond to stimulation events by undergoing further differentation. Thus, in our experiments lamin $\mathrm{A} / \mathrm{C}$ expression was induced in both in vitro cultures and more importantly in in vivo cultures after thioglycollate treatment. The experimental systems described here should allow in the future a dissection of the factors important for the switch on of lamin $\mathrm{A} / \mathrm{C}$ expression.

In vitrocullure. The in vilro experiments were possible because of the established in vitro culture conditions in which cells of the hemopoietic system differentiate into accessory cells and/or macrophages $[23,24]$. A detailed analysis of the differentiation process has shown that human peripheral blood monocytes pass through a phase of high accessory activity, which is reflected by their ability to stimulate $T$ lymphocytes to proliferate. If serum is omitted from the cultures the cells do not differentiate into macrophages but remain arrested in a state of high accessory activity and develop a dendriticlike morphology. If serum is present, the cells differentiate into macrophages. Culturing of rat bone marrow cells with and without serum also showed that under both conditions the cells differentiate into accessory cells, which display a dendritic morphology. Again cells without serum seem arrested at this stage, while in the presence of serum the cells differentiate further into macrophages.

Accessory cells are clearly distinct from monocytes and from macrophages, as demonstrated by their reactions with a number of markers and by their functional properties. However, their definition as a separate cell type and as an obligatory intermediate in the monocyte-macrophage pathway is still under discussion. Thus, their relation to other accessory cells, which occur in fully differentiated tissues such as the Langerhans cells of the epidermis and the follicular and interdigitating cells of lymphoid organs, is not yet clear. Certainly the accessory cells as observed in culture are not fully differentiated, since they can be induced to further differentiate into macrophages by components present in human $A B$ serum. While the finding that already the accessory cells express lamins $A / C$ does not settle the discussion, it is interesting that the lamin $\mathrm{A} / \mathrm{C}$-positive phenotype scems to be acquired at the monocyte/accessory cell boundary rather than, for instance, at the accessory cell/macrophage transition.

In the case of bone marrow-derived accessory cells and macrophages, all other cellular constituents which are present in a freshly prepared bone marrow died out during a few days of culture. Under the action of colonystimulating factors, only myeloid cells survive, which then further differentiate in a rather synchronous mat- 
ter. As already described in preceding papers [23, 24], blood monocytes virtually completely convert either into accessory cells or into macrophages. Because conversion of the lamin phenotype was also a quantitative phenomenon, this phenotype conversion could easily be attributed to individual cell types in the respective populations. Some lymphocytes present in the cultures were detected by their morphology and their characteristic nuclear shape. Only $5-10 \%$ of these lymphocytes were lamin A/C-positive. The reason for the existence of such a lamin A/C-positive subpopulation of lymphocytes is currently unclear.

Lamin A/C turn on. It is now possible to follow the switch on of lamin $\mathrm{A} / \mathrm{C}$ expression in a number of different systems in culture, i.e., in the rat BMC cells, and the human monocytes used here, in $\mathrm{T}$ lymphocytes treated with mitogens [30] and in teratocarcinoma cells after treatment with retinoic acid $[17,21,22]$. In addition lamin $\mathrm{A} / \mathrm{C}$ turn on is seen in the undifferentiated human promyelocytic leukemia cell line HL60 induced in vitro with the phorbol ester 12-O-tetradecanoylphorbol-13-acetate (TPA) or dimethylsulfoxide to differentiate along either the macrophage or the granulocytic pathway. This differentiation is accompanied by lamin A/C expression, which could be shown by Northern blots to be regulated at the transcriptional level [20]. HL60 grown under poor culture conditions in the absence of TPA also starts to express lamins A/C (our unpublished results).

Comparison of in vitro and in vivo results. In this in vitro study, precursor cells were almost completely converted into accessory cells or mature macrophages, as indicated by the bright nuclear decoration with lamin $\mathrm{A} / \mathrm{C}$-specific antibodies. A dramatic increase of lamin A/C-positive cells could be observed in the first 3 days of culture. In vivo $5 \%$ of macrophages were weakly positive at Day 0 , increasing to $80 \%$ of strongly positive cells at Day 6 of thioglycollate stimulation. A comparison of the in vitro and in vivo data suggests that differentiation as judged by lamin A/C expression occurs under our culture conditions, while in vivo an added stimulus, which is provided in our experiments by the thioglycollate stimulation, is required. We draw attention to the fact that growth factors are present in the in vitro culture medium and that such factors can induce differentiation of certain hemopoietic cell types. Whether a factor which holds the macrophages in a not-completely differentiated state until they are challenged might be present in vivo remains to be determined.

This work was supported in part by grants from the Deutsche Forschungsgemeinschaft (Grant Os-3 to M. O. and Grant SFB 236 project B5 to J. H. P.). We thank Diane Durkos-Smith for her comments on the manuscript.

\section{REFERENCES}

1. Gerace, L., and Burke, B. (1988) Annu. Rev. Cell Biol. 4, 335374.

Received April 6, 1990
2. Fisher, D. Z., Chaudhary, N., and Blobel, G. (1986) Proc. Natl. Acad. Sci. USA 83, 6450-6454.

3. McKeon, F. D., Kirschner, M. W., and Caput, D. (1986) Nature (London) 319, 165-175.

4. Peter, M., Kitten, G. T., Lehner, C. F., Vorburger, K., Bailer, S. M., Maridor, G., and Nigg, E. A. (1989) J. Mol. Biol. 208, 398-404.

5. Vorburger, K., Lehner, C. F., Kitten, G. T., Eppenberger, H. M., and Nigg, E. A. (1989) J. Mol. Biol. 208, 405-415.

6. Röber, R.-A., Sauter, H., Weber, K., and Osborn, M. (1990) J. Cell Sci., 95, 587-598.

7. Weber, K., Plessmann, U., and Traub, P. (1990) FEBS Lett. 261, 361-364.

8. Höger, T. H., Krohne, G., and Franke, W. W. (1988) Eur. J. Cell Biol. 47, 283-290.

9. Burke, B., and Gerace, L. (1986) Cell 44, 639-652.

10. Holtz, D., Tanaka, R. A., Hartwig, J., and McKeon, F. (1989) Cell 59, 969-977.

11. Vorburger, K., Kitten, G. T., and Nigg, E. A. (1989) EMBO J. 8, 4007-4013.

12. Beck, L. A., Hosick, T. J., and Sinensky, M. (1988) J. Cell Biol. 107, 1307-1316.

13. Webør, K., Plessmann, U., and Traub, P. (1989) FEBS Lett. 257, 411-414.

14. Worman, H. J., Yuan, J., Blobel, G., and Georgatos, S. D. (1988) Proc. Natl. Acad. Sci. USA 85, 8531-8534.

15. Lehner, C. F., Stick, R., Eppenberger, H. M., and Nigg, E. A. (1987) J. Cell Biol. 105, 577-587.

16. Stewart, C., and Burke, B. (1987) Cell 51, 383-392.

17. Röber, R.-A., Weber, K., and Osborn, M. (1989) Development 105, 365-378.

18. Prather, R. S., Sims, M. M., Maul, G. G., First, N. L., and Schatten, G. (1989) Biol. Reprod. 40, 123-132.

19. Guilly, M. N., Bensussan, A., Bourge, J. F., Bornens, M., and Courvalin, J. C. (1987) EMBO J. 12, 3795-3799.

20. Paulin-I evasseur, M., Scherbarth, A., Traub, U., and Traub, P. (1988) Eur. J. Cell Biol. 47, 121-131.

21. Lebel, S., Lampron, C., Royal, A., and Raymond, Y. (1987) J. Cell Biol. 105, 1099-1104.

22. Stuurman, N., Van Driel, R., De Jong, L., Meijne, A. M. L., and Van Kenswoude, J. (1989) Exp. Cell Res. 180, 460 466.

23. Gieseler, R. H. K., Röber, R. A., Kuhn, R. Weber, K., Osborn, M., and Peters, J. H., submitled for publication.

24. Peters, J. H., Ruhl, S., and Friedrichs, D. (1987) Immunobiology 176, 154-166.

25. Dexter, T. M., Garland, J., Scott, D., Scolnick, E., and Metcalf, D. (1980) J. Exp. Med. 152, 1036-1047.

26. Koski, I. R., Poplack, D. G., Blaese, R. M. (1976) in In Vitro Methods in Cell-Mediated and Tumor Immunology (Bloom, B. R., and David, J. R., Eds.), pp. 259, Academic Press, New York.

27. McMaster, W. R., and Williams, A. F. (1979) Eur. J. Immunol. 9, 426-433.

28. Gallily, R., and Feldman, M. (1967) Immunology 12, 197-203.

29. Dwyer, N., and Blobel, G. (1976) J. Cell Biol. 70, 581-891.

30. Traub, P., Scherbarth, A., Willingale-Theune, J., Paulin-Levasseur, M., and Shoeman, R. (1988) Eur. J. Cell Biol. 46, 478-490.

31. Osborn, M., Debus, E., and Weber, K. (1984) Eur. J. Cell Biol. 34, 137-143.

32. Kaufmann, S. H. (1989) J. Biol. Chem. 264, 13,946-13,955. 